\section{Are Viruses Organisms or Autocatalysts?}

(1) THE absence of a limiting surface between the material of a virus and its host; (2) the high speed of the transmission of its characteristic symptoms (10-30 cm. per hour) in the tissues of the host; (3) its rapid increase; (4) the vanishingly small quantities needed for inoculation, made me many years ago form the opinion that viruses are more properly regarded as autocatalytic substances than as specific organisms. From 1922 on, I have mentioned the idea in my lectures.

This view is now strikingly supported by Stanley's separation from a virus-infected plant of a crystallizable protein, which, when inoculated into a healthy one, produces the symptoms of the virus disease $^{1}$. From the work of Bawden, Pirie, Bernal and Fankuchen ${ }^{2}$, it further appears that the molecules of this protein are rod-shaped and are built up of sub-units of the same character.

The facts recently emphasized in Dr. John Caldwell's article ${ }^{3}$, namely, that viruses spread most rapidly from growing tissues, where presumably the sub-units of the protoplasmic proteins are in great abundance, and that they travel from cell to cell by way of the plasmodesmata, accord well with the autocatalytic theory. Furthermore, they cannot penetrate through a barrier of dead cells, or through unperforated cell-walls.

No doubt the present workers will test, or have already experimentally tested, the ability of Stanley's protein to catalyse its own production in the extracts from otherwise uninfected cells. It must be remembered that Olitsky has already reported that he has been able to cultivate tobacco mosaic in a simple medium presumably free from cells ${ }^{4}$.

Henry H. Dixon.

\section{School of Botany, \\ Trinity College, \\ Dublin.}

Dec. 24

\footnotetext{
1 Phytopathology, 28, 305 (1936).

Nature, 138, 1051 (Dec. 19, 1936).

Nature, 138, 1065 (Dec. 19, 1936).

- Science, 60, 593 (1924).
}

Spontaneous Chromosome Changes in Pollen Grains

IN preparations showing the first post-meiotic mitosis in pollen grains of two genera, Tradescantia and Hyacinthus, I find evidence of spontaneous structural changes in the chromosomes occurring with a high frequency. Some of these changes are of the kind that can be produced artificially by the action of X-rays on the post-meiotic resting stage. They depend on breaks and rejoins between chromosomes or chromatids, according to whether the changes occur before or after the chromosomes have split (Riley ${ }^{1}$, Mather unpub.). These breaks and rejoins lead to the formation of dicentric chromatids and acentric fragments (those having two or no centromeres or spindle attachment chromomeres respectively ${ }^{2}$ ). At anaphase and telophase the dicentric chromatids form bridges connecting the two daughter nuclei, while the fragments lie passively on the equator.

I have found bridges of this kind in T. virginiana $(2 n=18=3 x)$ (Fig. $1 a)$. One or more bridges may be present together with a corresponding number of fragments, although these are occasionally not visible. The free arms of the bridges may be equal (Fig. Ia) or unequal, showing that at least in some cases non-homologous chromatids have joined up. The difference of size between the chromosomes in this species, however, is slight, so that they are not individually recognizable. Cells containing these bridges often occur in groups of two or three, although the aggregate number of changes observed is only of the order of ten or twelve in each flower. The original frequency of change must be greater than this, since the results can be readily detected only at anaphase, and a small proportion of nuclei only are undergoing mitosis at any one time.

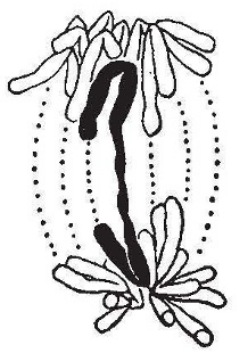

(a)

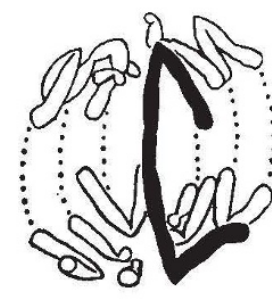

(b)
Fig. 1.

ANAPHASE OF POLLEN GRAIN DIVISION IN UNTREATED MATERIAL OF $(a)$ Tradescantia virginiana $(3 x=18)$ AND $(b)$ Hyacinthus orientalis var. "WILLIAM MANSFIELD" $(2 x=16)$. EACH CELL CONTAINS A DICENTRIC CHROMATID FORMING A BRIDGE. NO FRAGMENT IS VISIBLE. $\times 1600$.

In Hyacinthus orientalis variety "William Mansfield" $(2 n=16=2 x)$ (Fig. $1 b)$, similar bridges occur with a somewhat lower frequency, but acentric fragments have not usually been seen with them. The bridge is always formed from one of the long chromosomes, and its free arms are always equal. The separation of the remaining chromosomes is normal and there is no evidence of non-disjunction. In such cases, therefore, one of the chromatids of the bridge chromosome must have joined up with its sister, as may also happen with induced changes $\left(\right.$ Husted $^{3}$ ). Since fragments are rarely seen, and since the bridge appears to be approximately equal in length to the sum of the free arms (all the long chromosomes have median centromeres), it is presumably the ends that have joined. This conflicts with previous inferences of the inability of chromosome ends to fuse ${ }^{2}$.

These structures cannot be the result of crossing. over in inversions at meiosis, since one and not two sister chromatids form the bridge, and further, in the case of the diploid, the normal complement of chromosomes excludes the possibility of non-disjunction. They are therefore the result of spontaneous changes, and changes which differ in both character and frequency from those hitherto inferred.

\section{MARGaRET UPCOTT.}

John Innes Horticultural Institution, Merton, London, S.W.19.

\section{Dec. 17}

${ }^{1}$ Riley, H. P., Cytologia, 7, 131 (1936).

2Darlington, C. D., "Recent Advances in Cytology" (2nd ed., London, 1937).

${ }^{3}$ Husted, L., Genetics, 21, 537 (1936). 